available for all to know. These criteria could be as strict as necessary to ensure fair allocation of whatever funds can be made available. The investigation required for this need not be difficult, some preliminary work for assessing disability in chronic bronchitics having already been done. ${ }^{1}$

I would also have hoped that before stopping the issue of new invalid tricycles (currently $18000)$ the investigation should have been done to ensure that the mobility of those previously eligible could be extended at least as effectively by the provision of the new allowance. Only for that reason can its advantage be validated.

Government decisions for the disabled appear to be influenced by political pressure and by whims of public opinion more than by established clinical facts. In the case of invalid tricycle accident rates the distinction seems to have been forgotten between statistical probability for the comparison of groups and for the prediction of events likely for an individual. Until some research into the facts is published so that its standard of scientific inquiry can be judged Mr Ennals's assurance about the arrangements, even for existing invalid tricycle drivers, are unconvincing.

Rehabilitation Studies Unit,

University Department of

Orthopaedic Surgery,

Orths Margaret Rose

Edinburgh 'McGavin, C R, and Gupta, S P, and McHardy, G I R,
British Medical fournal, 1976, 1, 822.

\section{Royal College of General Practitioners}

SIR,-Dr Ian Capstick (5 February, p 373) wonders why the Royal College of General Practitioners is not very popular with GPs. May I tell him why the college repels one ancient ex-member but assure him that similar reasons repel quite experienced GPs who are 20 or 30 years younger than I am? May I also assure him that I still think the idea of the college was a good one, that I should like to see a fresh start, and that I am too old to have taste for grapes, whether sweet or sour?

(1) The college seems to claim that its members are an élite group, a magic circle of worthies entitled to be looked up to as representing "all that is best in general practice."

(2) It seems to promote clinical and managerial orthodoxies and enforce assent (or at least lip-service) to them on those who wish or think it prudent to join the circle. The fact that they are frequently expressed in unintelligible language (modules of un-health, sensory modalities) lends them a whiff of charlatanism. There is no place for infallible dogma in any of the sciences; this year's orthodoxy is often next year's laughable nonsense, and even the "laws of nature" remain hypotheses.

(3) The college gives the impression of being on the make. It has cornered the lucrative vocational training business and established the right to speak on behalf of all of us whereever there is power to be wielded or personal advancement to be had, without making much or any attempt to find out what we think.

(4) The business of faculties, provosts, censors, chains, and gavels may be well enough for institutions that date back to the 16 th century or even the 12 th but looks like a pompous charade or a comic turn in one that was born in the second half of the 20 th.

\section{Maldon, Essex}

DAvid CARGILI

SIR,-Dr Ian Capstick in his Personal View (5 February, p 373) expresses feelings which I am sure are common to many of us who, like him, entered general practice as first career choice with the ambition to practise good clinical medicine and who joined the Royal College of General Practitioners to further the cause of good medicine in general practice.

The college appears to the ordinary GP to have lost sight of the fact that good general practice is first and foremost about good clinical medicine. It has performed a useful function in trying to establish general practice as a specialty in its own right, but in doing this it has striven too hard to try to prove that general practitioners are different from other doctors. My view is that they are not. Good doctors from the time of Hippocrates and no doubt before that have always cared for the whole patient.

The matters which seem to be of great concern to the college at the present time, such as the dynamics and components of the consultation, are frills and luxuries when we hear frequent stories of patients going to their GPs with serious physical illnesses which are not investigated; where the patient is not properly examined and is given Valium tablets when he has a serious and treatable condition.

I am sure that the college would gain much more respect and support if it made serious efforts now to tackle the problems of bad clinical medicine and to give much more thought to how general practice should be organised to give the best clinical service, particularly in the large urban areas where most of the people live.

RAINE ROBERTS

Wythenshawe,

Manchester

\section{Self-poisoning with drugs}

SIR,-In reply to some points raised in correspondence (29 January, p 286) since the publication of my paper (1 January, $p 28$ ) it is probably right, as Dr F J Flint writes, that my quoted figure of 50 incidents of selfpoisoning in Sheffield in 1955 is too low. However, a proper search was made and all suspicious incidents in the casualty records such as "collapse" or "coma" were examined and compared with the inpatient notes, as clearly I was aware of the implications of the Suicide Act.

It is too early to tell whether the rising incidence of self-poisoning has reached a plateau. The suspicion of Drs $M M$ Sundle and $S M$ Amiel may be confirmed, but only further observation will establish this point. As for their concluding remarks, I firmly believe that too many people are taking too many hypnotic and psychotropic drugs for too long. The benzodiazepines may be extremely safe drugs, but this hardly justifies their use as the universal panacea.

Dr D J Pallis is also correct. I cannot justify my suspicion that the junior hospital doctors dispute led to the observed fall in the number of admissions during December 1975. The

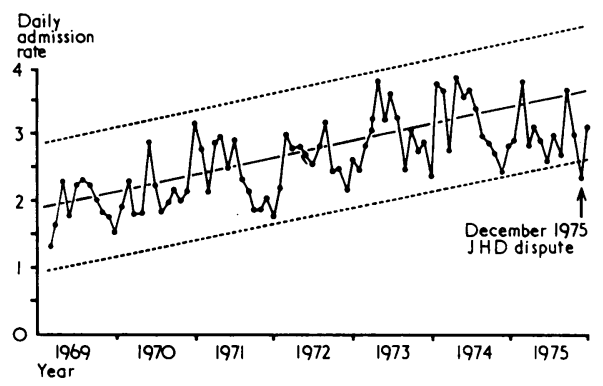

Monthly average daily admission rate due to self-poisoning at three Sheffield hospitals (1969$75)$. The continuous straight line is a regression line, the parallel dotted lines are arbitrary confidence limits.

data do not bear statistical scrutiny. If, however, the facts are represented graphically (see figure) the theory at least looks plausible. If I have planted the seeds of doubt and encouraged others to examine critically their own material in a similar fashion I will have served my purpose.

D I R JONES

Department
Medicine, Universi

\section{Multiple courses of ancrod (Arvin)} therapy

SIR,-We read with interest the report by Drs N G Kounis and A W Howel Evans (29 January, p 291) of the patient who received, over six years, five separate courses of ancrod (Arvin) without anaphyloid reaction or the development of drug resistance. We have also recently described ${ }^{1}$ a similar patient with recurrent thromboembolic disease who received ancrod for a total of 45 days but thereafter developed complete resistance. After an initial 19 days of ancrod anticoagulation in our patient was changed to warfarin. Six days later, because of the recurrence of deep vein thrombosis, ancrod was recommenced and continued for a further 26 days. It was then stopped for $12 \mathrm{~h}$ to allow surgery for plication of the inferior vena cava, but this had to be postponed because of pneumonia. On restarting ancrod for the third time the patient was found to have developed total resistance as judged by a modification of the test described by Pitney et $a l^{2}$; this was still present two months later.

The reasons for the development of drug resistance after repeated courses of ancrod in our patient and not in the one described by Drs Kounis and Evans are not clear but it could be the shorter courses given to the latter and the simultaneous administration of corticosteroids. If multiple courses of ancrod are found to be useful in the treatment of recurrent thromboembolic disease the onset of drug resistance might be delayed or prevented by limiting the duration of individual courses and increasing the intervals between each course.

N C Thomson A W HUTCHEON J H DAGG

University Department of Medicine,

Western Infirmary Glasgow

1 Thomson, N C, Hutcheon, A W, and Dagg, J H, 2 Pitney, W R, et al, Lancet, 1969, 1, 79. 